Research Article

\title{
Pharmacovigilance analysis in a rural tertiary care hospital in North India: a retrospective study
}

\author{
Atal Sood $^{1}$, Vivek Sood ${ }^{1}$, Himani Prajapati ${ }^{1}$, Aradhna Sharma ${ }^{1}$, \\ Rekha Bansal', Vikram Mahajan ${ }^{3}$
}

\author{
${ }^{1}$ Department of Pharmacology, \\ ${ }^{2}$ Department of Pulmonary \\ Medicine, ${ }^{3}$ Department of \\ Dermatology, Dr. RPGMC, \\ Kangra at Tanda, Himachal \\ Pradesh, India
}

Received: 09 May 2016

Accepted: 08 June 2016

*Correspondence to:

Dr. Atal Sood,

Email: atalsood7@gmail.com

Copyright: (C) the author(s), publisher and licensee Medip Academy. This is an openaccess article distributed under the terms of the Creative Commons Attribution NonCommercial License, which permits unrestricted noncommercial use, distribution, and reproduction in any medium, provided the original work is properly cited.

\begin{abstract}
Background: The main motive of PvPI (Pharmacovigilance Programme of India) is to collect valuable data so that signals can be generated from reported adverse drug events (ADEs). It also tries to establish their causality so that ADEs can be labelled as adverse drug reactions (ADRs) beyond any doubt.

Methods: This retrospective observational study done in rural set up tertiary care teaching hospital collected data through voluntary reporting in ADR form of PvPI for period of 6 month. Causality assessment was done using WHO causality assessment scale.

Results: In 150 reported cases, majority ADRs were due to tuberculosis, cancer and HIV treatments. Gastrointestinal tract and central nervous system were the major organs involved. Most ADRs occurred within first day of drug intake. Around $15 \%$ required hospitalization. 55\% ADRs were probable and $41 \%$ were possible in nature. Vertigo and depression was most frequent ADR in MDR therapy. Rashes, pruritis, fever and joint pain was frequent in antiretroviral therapy. Dysguesia, dizziness, nausea, vomiting and constipation was frequent in patients taking anticancer drugs. Platins and antibiotics used for cancer therapy cause most cancer treatment ADRs.

Conclusions: ADRs add to hospitalization expenses, insurance costs and increase in work loss days besides addition to patient suffering. Prior knowledge can help in better prescriptions and prevent valuable resource loss. Reasons for under-reporting of ADRs can be complacency, ignorance, lack of financial incentives for reporting, fear of litigation, claims of compensation and lack of time in busy hospital schedules.
\end{abstract}

Keywords: Pharmacovigilance in India, ADE, DOTS plus ADR, Antiretroviral therapy ADR, Chemotherapy ADR

\section{INTRODUCTION}

WHO defines pharmacovigilance as the science and activities relating to the detection, assessment, understanding, reporting and prevention of adverse effects or any other drug-related problem. ${ }^{1}$ The main emphasis of pharmacovigilance is to detect signals generated as adverse drug events (ADEs) and to establish their causality so as to label them with certainty as adverse drug reactions (ADRs). ADRs themselves are defined by WHO as an unintended and noxious response to a drug that occurs at doses normally used for the prophylaxis, diagnosis, or therapy of diseases, or for the modification of physiological function. ${ }^{2}$ Adverse reactions to drugs are the most common cause of iatrogenic disease. ${ }^{3}$ Pharmacovigilance programme started in India in year 2010 but actual data collection in hospitals has started in recent times only.

ADEs have an adverse effect on the society and increase the number of work loss days, morbidity and mortality (Table 1).

The objective of this study was to find out commonly reported ADRs in Dr. RPGMC, Kangra at Tanda, 
Himachal Pradesh, India and assess the severity and causality.

\section{Table 1: ADEs impact according to European Commission. ${ }^{4,5}$}

\begin{tabular}{|ll|}
\hline Patients admitted in hospital & Percentage \\
\hline Patient deaths reported & $0.3 \%-5 \%$ \\
\hline $\begin{array}{l}\text { Patients reported with ADE during their } \\
\text { hospital stay }\end{array}$ & $3.5 \%$ \\
\hline
\end{tabular}

\section{METHODS}

The study was conducted at ADR monitoring center (AMC) of Dr. RPGMC, Kangra at Tanda; a 585-bedded rural tertiary care teaching hospital after approval of institutional ethics committee. This was a retrospective observational study. Data was collected through voluntary reporting by health-care professionals (HCP) in standard IPC-PvPI prescribed suspected ADR reporting form for period $1^{\text {st }}$ April to $30^{\text {th }}$ September 2015 (6 month). Causality assessment of ADEs was done by causality assessment committee using WHO causality assessment scale.

\section{RESULTS}

The data was analysed for age and gender distribution, segregation of ADEs was done on basis of organ systems involvement, severity and duration followed by causality assessment. Maximum cases were observed in adults. Mean age was $42.3 \pm 16.2$ years. (Figure 1) Almost equal numbers of ADEs were reported in males and females.

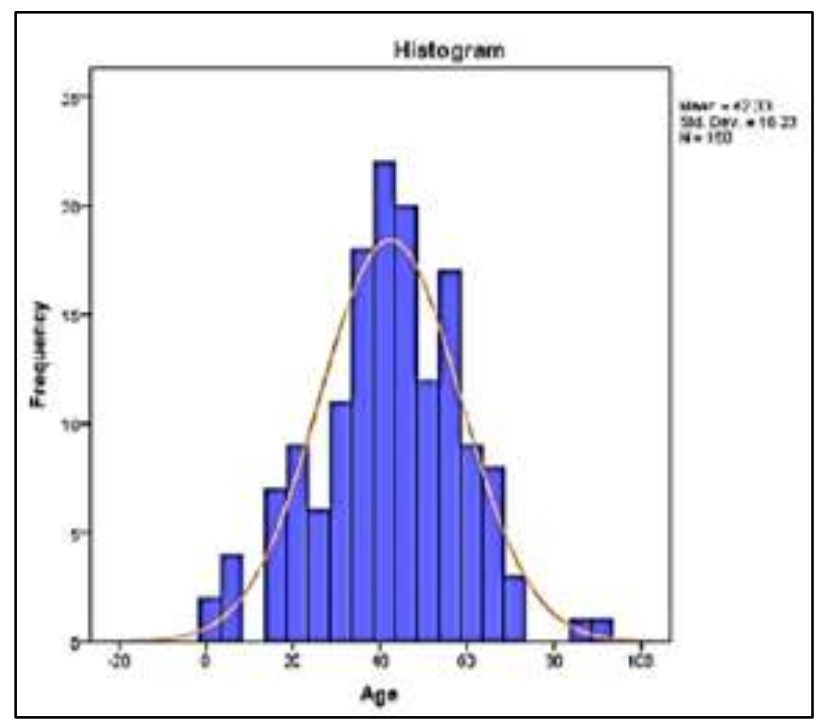

Figure 1: Age distribution of patients having ADEs.

\section{ADEs on basis of disease therapy}

50 ADEs were reported among patients taking antitubercular therapy. 39 among these were reported by patients on Category IV regime. Under PMDT, 11 ADEs were reported by patients on first line antitubercular drugs and 1 was reported by patient taking category $\mathrm{V}$ regime (XDR TB). 45 ADEs were reported by patients receiving cancer chemotherapy. 23 ADEs were reported by patients on antiretroviral therapy (ART) (Figure 2).

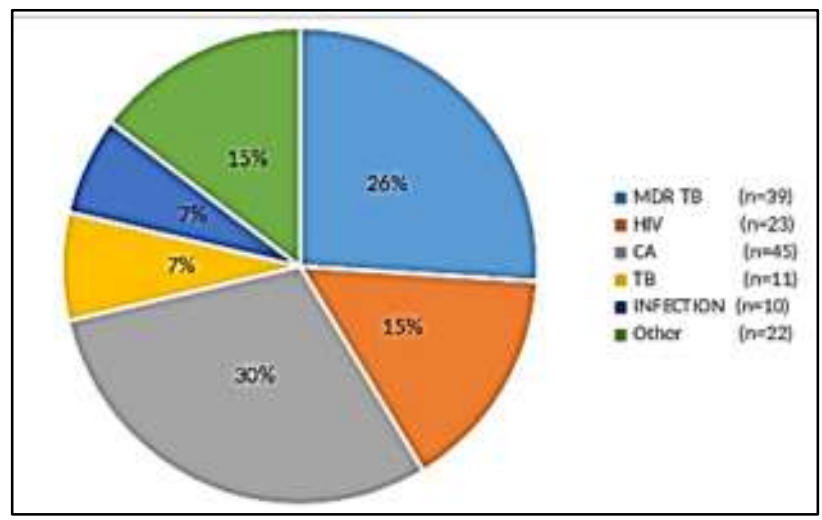

Figure 2: Disease treatments causing ADEs.

\section{System based ADEs}

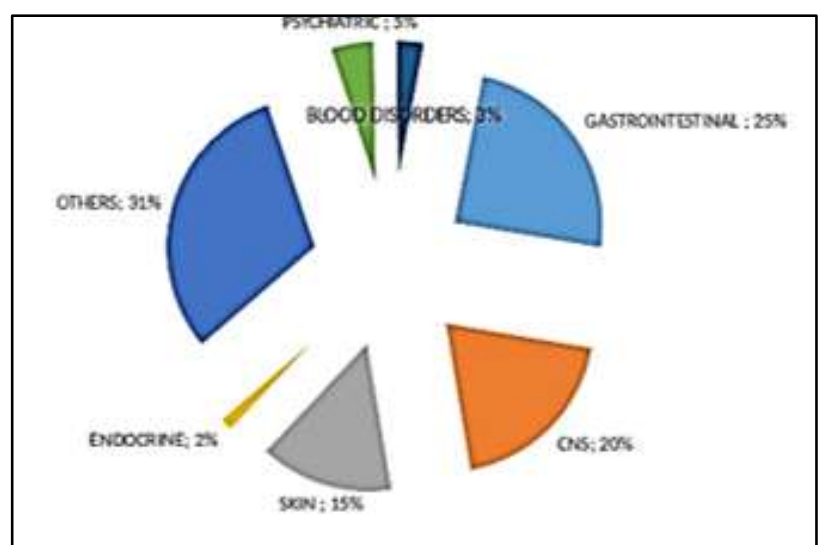

Figure 3: System based distribution of adverse drug events.

Majority of ADEs were involving the gastro-intestinal system and included nausea, vomiting, gastritis, anorexia, diarrhoea, constipation, dysguesia, dysphagia, hiccups, xerostomia, abdominal pain, glossitis, oral ulceration, and hepatitis. CNS ADEs were next in the order of frequency and the patients experienced dizziness, insomnia, vertigo, peripheral neuropathy, headache, amnesia, slurred speech, confusion, tremors, numbness and tinnitus. Dermatological ADEs included rashes, pruritis, hyperpigmentation, nail discoloration, fixed drug eruption, alopecia, vascular eruption, acute urticaria and Steven Johnson Syndrome. Psychiatric ADEs had psychosis, depression and irritability as their features. ADEs involving the hematological system included severe anemia and thrombocytopenia. Gynaecomastia was the sole endocrine ADE observed in this study. ADEs which could not be grouped as an organ system for ease of compiling the data included joint pains, hyperuricemia, 
urine discoloration, fever, asthenia, fatigue, cough, dyspnea, gum hyperplasia, shivering, blurred vision, sputum discoloration, hoarseness of voice, polyuria and hypotension (Figure 3).

\section{Time latency of ADEs}

Majority of ADEs in the study were acute in onset and lasted for less than one day; this was followed by subacute to chronic ADEs lasting about couple of weeks to months. However, $60.66 \%$ patients had ADEs that developed within 10 days of drug administration (Figure 4).

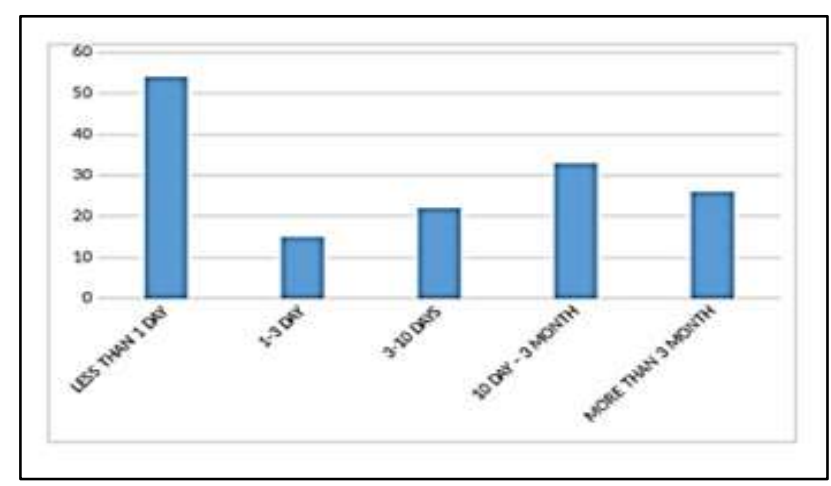

Figure 4: Time latency of adverse drug events.

\section{Poly-pharmacy}

Number of ADEs increased with the increase in number of prescribed drugs. This can partly be due to increased contribution of individual drugs and partly due to increase in possibility of increased drug-drug interactions (Table 2).

Table 2: Relation of number of drugs prescribed and their relation with number of ADEs.

\begin{tabular}{|ll|}
\hline Number of drugs prescribed & Number of ADEs \\
\hline Less than $3(n=98)$ & 1 to 3 \\
\hline More than $3(n=52)$ & 2 to 5 \\
\hline
\end{tabular}

\section{Seriousness}

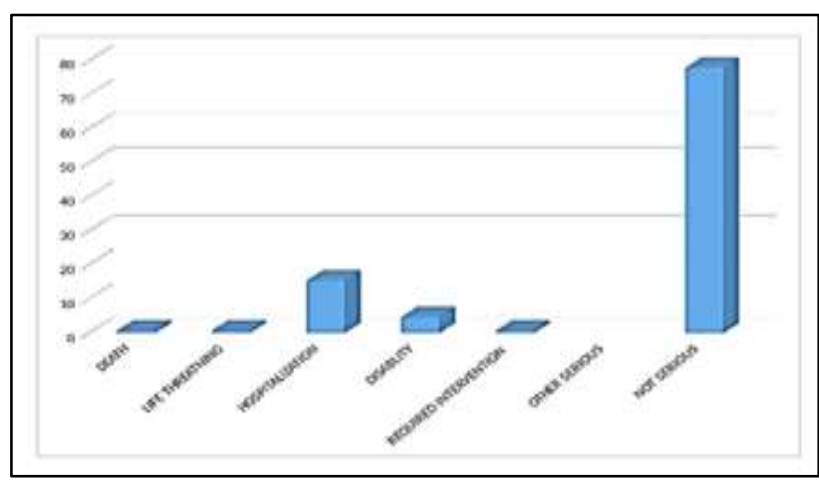

Figure 5: Severity of adverse drug events.
Hospitalization was required in 23 patients and 7 patients developed disability due to ADEs adding to financial costs, loss of man hours and deterioration of quality of life. Majority of patients $(n=117)$ experienced ADEs which were non-serious. However death was reported in only one case. Similarly one patient experienced life threatening ADE (Figure 5).

\section{Causality assessment}

Causality assessment of the cases was done by the causality assessment committee of hospital and it was observed that 83 patients $(55.3 \%)$ had probable ADEs due to the drugs they undertook and 62 patients (41.3\%) had possible ADEs. Certainty to ADEs was ascribed in only 5 patients (Figure 6).

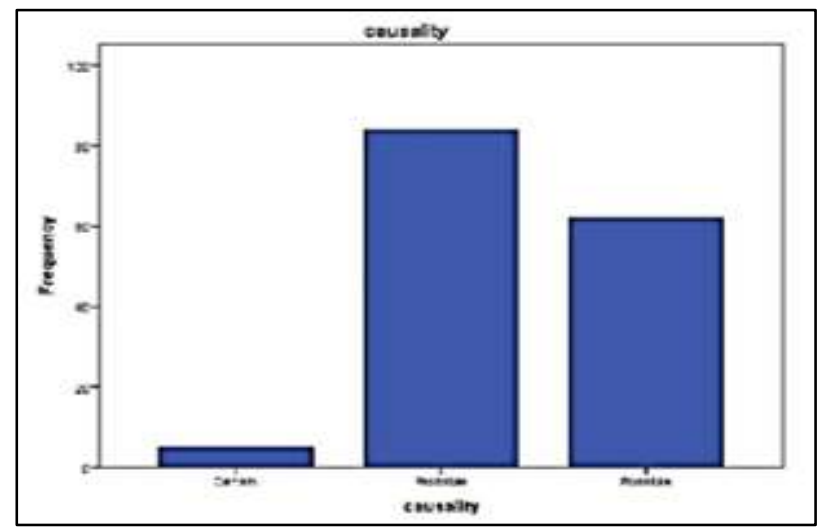

Figure 6: Causality assessment of adverse drug events.

\section{Common drugs causing ADEs}

\section{Tuberculosis therapy}

Commonest drugs causing ADEs observed in this study were DOTS-Plus anti-tubercular drugs. As high as 39 patients out of total 88 (44\%) on MDR therapy in Chest and TB clinic reported with ADEs. Culprit drugs include levofloxacin or ofloxacin, cycloserine or para amino salicylic acid (PAS), ethionamide, pyrazinamide, ethambutol and kanamycin. Amongst these MDR patients, vertigo and depression were found in $18 \%$ followed by nausea and anorexia in $15 \%$, psychosis and insomnia in $13 \%$ and joint pains, vomiting and ototoxicity in $10 \%$ of patients on such therapy. In patients taking category 1 antitubercular treatment, the commonest ADEs were rashes, pruritis, urine discoloration and hepatitis $(25 \%)$.

\section{Antiretroviral therapy}

ART regimes TLE (tenofovir, lamivudine, efavirenz) ZLN (zidovudine, lamivudine, nevirapine) accounted for 10 ADEs each. In this period 23 patients out of total 867 $(2.65 \%)$ taking ART in ART clinic were reported with ADEs. Among these, 10 patients were on TLE, 10 patients on ZLN while one patient each was on SLE 
(stavudine, lamivudine, efavirenz) LAN (lamivudine, abacavir, nevirapine) and TLN (tenofovir, lamivudine, nevirapine). Among the patients on TLE (10) $30 \%$ experienced rashes and pruritis, followed by dizziness and swelling in the face in $20 \%$. $10 \%$ of the patients on TLE had hepatitis, insomnia, tinnitus, and thrombocytopenia. Patients who received ZLN (10) 30\% experienced fever, followed by nausea, joint pains, peripheral neuropathy, dizziness, mental confusion and oral ulceration in $20 \%$. $10 \%$ complained of rashes, depression and dysguesia.

\section{Anticancer therapy}

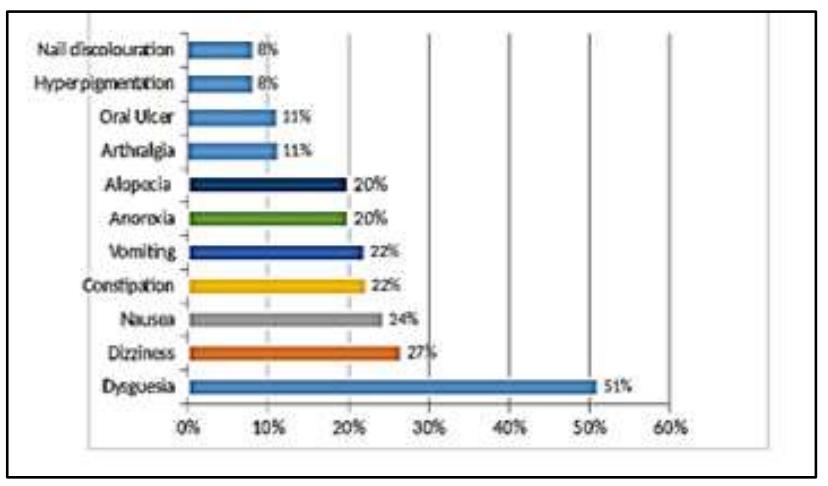

Figure 7: Common ADEs caused by anticancer drugs.

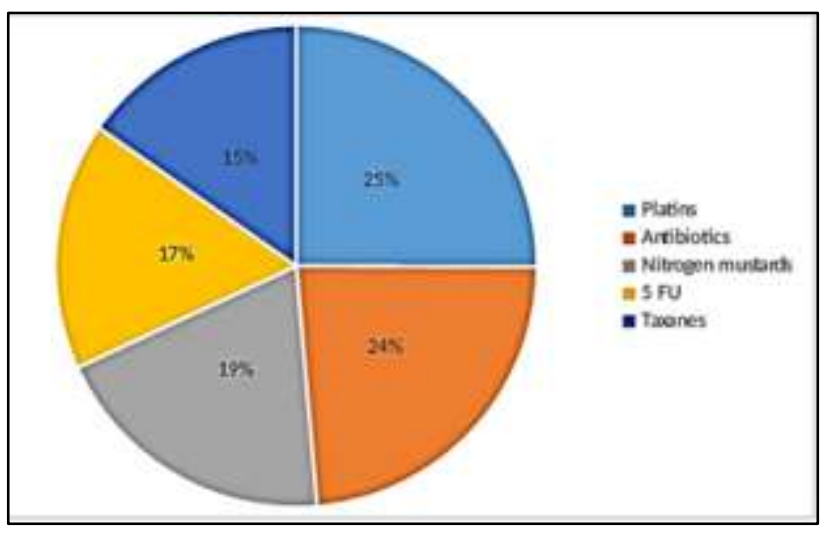

Figure 8: Common anticancer drug groups causing ADEs.

Among 45 patients having ADEs of various carcinomas, a total of 121 ADEs were found. 27 patients $(60 \%)$ were females and $18(40 \%)$ were males. Among the different cancers, breast carcinoma in 11 patients was commonest (24.4\%), followed by ovarian carcinoma in 7 (15.5\%), colon carcinoma in $6(13.3 \%)$ and non-Hodgkin's lymphoma and lung carcinoma in 5 each (11.1\%). Commonest ADEs found were dysguesia and dizziness among others. (Figure 7) Platinum containing compounds, antibiotics and nitrogen mustards used in chemotherapy caused most of the ADEs. (Figure 8) Doxorubicin was the commonest among the anticancer drugs causing ADEs (15 ADEs). Cyclophosphamide and 5-fluorouracil caused ADEs in 12 patients each. ADEs due to carboplatin was found in 10 patients.
Commonest ADEs observed with a combination of irinotecan with 5-flurouracil for the treatment of carcinoma colon were dizziness, dysguesia and vomiting observed in $50 \%$ of the patients while diarrhea was complained by $33 \%$ of the patients. Among the patients receiving a combination of doxorubicin with cyclophosphamide and vincristine for NHL, $60 \%$ of the patients experienced dysguesia while peripheral neuropathy and alopecia were complained by $40 \%$ of the patients receiving treatment. 3 patients of carcinoma breast had received a combination of doxorubicin with cyclophosphamide and 5-flurouracil with $33 \%$ of the patients complained of nausea and dysguesia. 3 patients of carcinoma breast and 1 patient of carcinoma colon received a combination of doxorubicin with cyclophosphamide and had nausea and alopecia as chief complaints $(66 \%)$.

Other anticancer drugs commonly observed in this study included paclitaxel (7 ADEs), vincristine (6 ADEs), irinotecan (4 ADEs), docetaxel (3 ADEs), gemcitabine (3 ADEs) and cisplatin (2 ADEs) among 45 patients.

Among the antibiotics, 4 reported ADEs were due to penicillins and 3 ADEs were due to ceftriaxone. 2 ADEs were due to fixed drug combination of ofloxacin and ornidazole.

\section{DISCUSSION}

Adverse drug reactions are different from the adverse drug events in the fact that adverse drug reactions are well documented and known. Adverse drug events are suspected to be due to drugs and signals picked up in pharmacovigilance help in documenting ADEs as ADRs. Different pharmacovigilance studies report different ADE rates. Voluntary spontaneous reporting of adverse reactions has proven to be an effective way in early signal generation and caution that a drug is causing an adverse event. Despite many efforts in India in the form of continuing medical education (CME), MCI mandate, publicity in the media, availability of smartphone based apps for android and apple platforms (https://medwatcher.org/mobile), toll free number for voluntary reporting (18001803024 Monday to Friday 9:30 - 5:30), the PvPI is deficient compared with the legally mandated system in the United Kingdom, Sweden, New Zealand, Denmark and Canada. ${ }^{6}$ Adverse drug reactions add to hospitalization expenses, insurance costs and increase in work loss days besides addition to patient suffering. At the community level it puts strain to the limited public health resources in the developing world. Knowledge of ADR rates can be a useful tool in prescribing as drugs with higher $\mathrm{ADR}$ rates can be replaced with better available drugs. Further, previous knowledge can help avoiding drugs with higher rate of fatality. Mandatory periodic safety update reports (PSURs) by pharmaceutical companies have helped in premature drug withdrawal in many cases like CETP inhibitors. ${ }^{7}$ Similar fate was met with an endocannabinoid 
CB1 receptor antagonist (rimonabant) which was suspended on the recommendations of EMEA due to its psychiatric side effects like anxiety and depression within two years of approval as a first in its class drug, as an adjunct to diet and exercise in treating obesity. ${ }^{8}$

In this study the numbers of cases in 30-50 years age group were greater than other groups in this study in concordance with one study in Brazil. No gender preponderance was seen in this study in concordance with Brazilian study. ${ }^{9}$ The frequency of ADEs in this study was more in oncology and medicine specialties similar to a study in brazil which reported incidence of ADEs higher in patients attending orthopaedic (25\%), general medicine (22\%), and oncology (16\%) specialities.9 As documented, most ADEs develop within 10 days of drug administration. ${ }^{10}$ As for the time latency for developing ADEs, $60.66 \%$ reported within 10 days of drug therapy. This is dissimilar to a study with an overwhelming $78 \%$ patients reporting with ADEs during the first 10 days. ${ }^{11}$ This further emphasizes close patient monitoring and caution during drug initiation till a week after for ADEs. Major organ systems involved in this study were gastrointestinal (24\%), CNS (20\%), skin (15\%), endocrine $(2 \%)$ and others $(30 \%)$. This is in discordance with the Brazilian study showing gastrointestinal involvement in $14 \%$, CNS in $9 \%$, dermatologic ADEs in overwhelming $34 \%$ and metabolic in $16 \%$ of patients. ${ }^{9}$ However, both these studies conclude hematologic ADEs as rare and in $3 \%$ of patients. ${ }^{9}$

Causality assessment of ADEs was done by using WHO Causality assessment scale and it was found that majority of the patients $(55.33 \%)$ had ADEs which were probable, since in all these cases there was reasonable time relationship between taking the drug and event occurring; events corresponded to what is known of the drug; events ceased after drug de-challenge and the events couldn't be explained by the natural history of disease. In $41.33 \%$ of the cases of ADEs, they were designated as possible since the time relationship was reasonable, the events corresponded to what is known of the drug, information of drug de-challenge were unclear and the events could readily have been a result of the natural history of disease or therapy. Certainty in ADEs could only be ascribed to $3.3 \%$ of patients as they had plausible time relationship to drug administration and event, event couldn't be explained by the natural history of disease or other drugs and events ceased plausibly with drug de-challenge. This is in coherence to similar studies from India. ${ }^{11,12} \mathrm{Re}-$ challenge was not attempted for ethical reasons.

Three major categories of drug treatments caused most ADEs in this study. These are drugs for MDR TB (DOTS-Plus), ART for HIV and various carcinoma therapies. In DOTS-Plus treatment, overall pattern of adverse reactions in this study was comparable to earlier studies. ${ }^{13-15}$ This is in contrast to a study from central India and other similar studies which reported gastrointestinal symptoms (nausea, vomiting and mild gastritis) as the most-common adverse reactions, however, these are second in the order of frequency in this study. ${ }^{13,16-18}$ An important observation in this study was the fact that despite gastrointestinal ADEs, no patient quitted or changed DOTS-Plus therapy. Insistence on treatment continuation by HCPs and family could be an important factor for this. Quinolones and ethionamide were found to be culprit drugs after causality assessment. These ADEs can be mitigated by pretreating the patients one hour prior with domperidone or $\mathrm{H} 2$ blockers. Psychosis was also common ADEs in this study as already mentioned. Cycloserine is known to cause psychosis as a late manifestation as mentioned in previous studies. ${ }^{19}$ These patients were started with PAS after omitting cycloserine from DOTS-Plus regimen. Arthralgia as found in this study could be due to pyrazinamide and quinolones. Pyrazinamide produces arthralgia and arthritis by causing hyperuricemia while quinolones cause cartilage damage, Achilles tendon rupture and tendinitis. ${ }^{20}$ Vertigo was having definite causal relationship with kanamycin, as all aminoglycosides are known to be vestibulotoxic due to the production of free radicals. ${ }^{21}$ Aminoglycosides induce an increase of free radicals either by stimulating the $\mathrm{N}$ methyl-D-aspartate (NMDA) receptor or by the binding to iron. $^{22}$ Thus the hair cells of the inner ear are damaged due to this changed milieu leading to vertigo. No ocular ADEs were reported due to DOTS-Plus in this study despite ethambutol being known to cause visual disturbance and this could be due to less patient number. ${ }^{23}$

Various regimes used for ART in the place of study were TLE, ZLN, SLE, TLN and LAN. More ADEs were reported in TLE and ZLN regime. Non-nucleoside reverse transcriptase inhibitors (NNRTIs) efavirenz and nevirapine were the culprit drugs after causality assessment for rashes and pruritus. Findings of the study are in agreement to a similar study which reports the incidence of hepatitis with efavirenz as $8 \% .{ }^{24}$ Few number of cases of rash $(10 \%)$ and negligible hepatotoxicity in patients taking nevirapine is in concordance with another study from India which reports skin rash $(7.5 \%)$ and hepatotoxicity $(3.1 \%)$ respectively. ${ }^{25}$ This is in contrast to a South African study which reported neuropathy (21\%), rash (15\%), cough (12\%), lipodystrophy (6\%) and dizziness $(4 \%)$ as chief ADEs. ${ }^{26}$ Peripheral neuropathy along with pancreatitis is usually associated with using stavudine or didanosine and there was only a single patient on stavudine. None of the patient in the study suffered from lipodystrophy which is strongly associated with stavudine use. Latest WHO updates do not recommend use of stavudine as a first line drug for ART. ${ }^{27}$ The results are also in disagreement with another study which claims neuropathy as the most prevalent ADE. ${ }^{28}$ Tenofovir was part of ART in 11 patients and these patients were better off in respect ADEs as it is generally well tolerated. Similarly lamivudine which was part of ART in all patients is one of the least toxic antiretroviral drugs. ${ }^{29}$ The high frequency of dizziness 
(20\%) in this study can be explained by the fact that both tenofovir and lamivudine are known to cause dizziness. ${ }^{30}$

Cancer chemotherapy is known to cause plethora of ADEs. Female gender preponderance in this study is in coherence with South Indian study which reported 500 ADEs in 195 patients over a period of 2 years with female preponderance $(56 \%) .12$ However; this is in contrast to another study from eastern part of India which had male predominance. ${ }^{31}$ Percentages of different cancers in this study are in partial agreement with other studies which report carcinoma breast and carcinoma lung to be the commonest. $^{31}$ These findings correlate with that from south India which report ovarian carcinoma to be the second most common. ${ }^{12}$ The percentages of ADEs in this study are in agreement with few other studies which report nausea and vomiting as commonest ADEs. ${ }^{31,32}$ This differs from a study done in Nepal which reports neutropenia as the commonest ADE. ${ }^{33}$ Nausea and vomiting are anticipated as most cytotoxic agents cause direct stimulation of chemoreceptor trigger zone. Another study reports constipation as the chief ADE. ${ }^{34}$ Since chemotherapy usually affects organ systems with rapid cell turnover like mucus membrane, bone marrow, skin and its appendages ADEs like alopecia, myelosupression and oral ulceration are anticipated. Platinum compounds caused many ADEs in this study in correlation with the South Indian and Nepalese study which reports platinum compounds and nitrogen mustard to cause most ADEs. ${ }^{12,33}$

The limitations of this study in India, several patients also take AYUSH (Ayurveda, Unani, Sidhha and Homeopathy) therapies concurrent to allopathic treatments which often contain heavy metals. Drug interactions with these alternative systems of medicine in India are often unreported and may lead to alteration in outcomes of drug reactions. Efforts should also be made for mandatory reporting of ADEs as voluntary reporting has its own pitfalls. There can be under-reporting of ADRs by HCPs due to complacency, ignorance, lack of financial incentives, fear of litigation and compensation claims and lack of time in busy hospital schedules.

\section{ACKNOWLEDGEMENTS}

Authors extend deepest gratitude to all healthcare providers for voluntarily reporting the adverse drug events and colleagues for providing valuable guidance and mentorship.

Funding: The data was collected under the aegis of Indian Pharmacopoeia Commission (National Coordinating Centre - Pharmacovigilance Programme of India) and no financial cost accrued to the patients. Conflict of interest: None declared

Ethical approval: The study was approved by the Institutional Ethics Committee, Approved vide no: HFWH-DRPGMC/Ethics/2016 protocol no.20/2016

\section{REFERENCES}

1. World Health Organization. Safety of medicines: a guide to detecting and reporting adverse drug reactions. Geneva, Switzerland; 2002.

2. World Health Organization. Technical report series no. 425. Geneva, Switzerland: World Health Organization. International drug monitoring: the role of the hospital; 1966;1-24.

3. Leape LL, Brennan TA, Laird N, Lawthers AG, Localio AR, Barners BA, et al. The nature of adverse events in hospitalized patients- Results of Harvard medical practice study II. N Engl J Med. 1991;324:377-84.

4. Rehan HS, Vasudev K, Tripathi CD. Adverse drug reaction monitoring: knowledge, attitude and practices of medical students and prescribers. Natl Med J India. 2002;15(1):24-5.

5. Rishi RK, Patel RK, Bhandari A. Opinion of physicians towards adverse drug reactions reporting results of pilot study. J Commun Nutr Health. 2012;1(1):25.

6. Brunton LL, Lazo JS, Parker KL. Goodman and Gilman's. The pharmacological basis of therapeutics. In: Oates JA, editors. The science of drug therapy. $11^{\text {th }}$ ed. New York: Mc Graw Hill; 2006;135.

7. Hewing B, Fisher EA. Rationale for cholesteryl ester transfer protein inhibition. Curr Opin Lipidol. 2012;23(4):372-6.

8. Mingfang LI, Bernard MY. Pharmacotherapy for obesity. Br J Clin Pharmacol. 2009;68(6):804-10.

9. Lobo A, Germana M, Gerley J. Adverse drug reaction monitoring; support for pharmacovigilance at a tertiary care hospital in northern Brazil. BMC Pharmacol Toxicol. 2013;78(3):1-7.

10. Eileen G, Hollcend, Phevm D, Frank V, Degrig M. D. drug induced disorder. D family Physician. 1997;2:10.

11. Gor AP, Desai SV. Adverse drug reactions (ADR) in the in patients of medicine department of a rural tertiary care teaching hospital and influence of pharmacovigilance in reporting ADR. Indian $\mathbf{J}$ Pharmacol. 2008;40(1):37-40.

12. Sharma A, Kumari MK, Manohar HD, Bairy KL, Thomas J. Pattern of adverse drug reactions due to cancer chemotherapy in a tertiary care hospital in South India. Perspect Clin Res. 2015;6(2):109-15.

13. Shinde KM, Pore SM, Bapat TR. Adverse reactions to first-line anti-tuberculous agents in hospitalised patients: pattern, causality, severity and risk factors. IJMS. 2013;4(1):16-21.

14. Furin JJ, Mitnick CD, Shin SS, Bayona J, Becerra $\mathrm{MC}$, Singler JM, et al. Occurrence of serious adverse effects in patients receiving community-based therapy for multidrug-resistant tuberculosis. Int $\mathrm{J}$ tuberc lung dis. 2001;5(7):648-55.

15. Joseph P, Rao DVB, Mohan NS, Fredrick JS, Ramachandran R, Raman B, et al. Outcome of standardized treatment for patients with MDR-TB 
from Tamil Nadu, India. Indian $\mathbf{J}$ Med Res. 2011;133:529-34.

16. Tak DK, Acharya LD, Gowrinath K, Rao Padma GM, Subish P. Safety evaluation of antitubercular therapy under revised national tuberculosis control programme in India. J Clin Diagn Res. 2009;3:1395401.

17. Schaberg T, Rebhan K, Lode H. Risk factors for sideeffects of isoniazid, rifampin and pyrazinamide in patients hospitalized for pulmonary tuberculosis. Eur Respir J. 1996;9:2026-30.

18. Hire R, Kale AS, Dakhale GN, Gaikwad N. A prospective, observational study of adverse reactions to drug regimen for multi-drug resistant pulmonary tuberculosis in central India. Mediterr $\mathrm{J}$ Hematol Infect Dis. 2014;6(1):e2014061.

19. Vega P, Sweetland A, Acha J. Psychiatric issues in the management of patients with multidrug-resistant tuberculosis. Int J Tuberc Lung Dis. 2004;8:749-58.

20. Arora VK, Tumbanatham A. Severe arthropathy with ofloxacin in two cases of MDR tuberculosis. Int J tuberc lung dis. 1998;2(11):941-6.

21. De Jager $P$, van Altena R. Hearing loss and nephrotoxicity in long-term aminoglycoside treatment in patients with tuberculosis. Int $\mathbf{J}$ Tuberc Lung Dis. 2002;6:622-7.

22. Darlington CL, Smith PF. Vestibulotoxicity following aminoglycoside antibiotics and its prevention. Curr Opin Investig Drugs. 2003;4(7):8416.

23. Kahana LM. Toxic ocular effects of ethambutol. Can Med Assoc J. 1987;137:213-6.

24. Sulkowski MS, Thomas DL, Chaisson RE, Moore RD. Hepatotoxicity associated with antiretroviral therapy in adults infected with HIV and the role of hepatitis C or B virus infection. JAMA. 2000;283:7480 .

25. Nagpal M, Tayal V, Kumar S, Gupta U. Adverse drug reactions to antiretroviral therapy in AIDS patients at a tertiary care hospital in India: A prospective observational study. Indian J Med Sci. 2010;64:245-52.

26. Masenyetse LJ, Manda SO, Mwambi HG. An assessment of adverse drug reactions among HIV positive patients receiving antiretroviral treatment in South Africa. AIDS Res Ther. 2015;12:6

27. WHO. Rapid advice. Antiretroviral therapy for HIV infection in adults and adolescents 2009. Available at http://www.who.int/hiv/pub/arv/rapid_advice_art.pdf.

28. Reddenna L, Basha SA, Gopal DV, Krishna TR. Highly active antiretroviral therapy: incidence of adverse drug reactions. Int $\mathrm{J}$ of Allied Med Sci and Clin Research. 2013;(1):25-30.

29. Brunton LL, Chabner B, Knollman B. Goodman and Gilman's The Pharmacological basis of Therapeutics. In: Flexner $\mathrm{C}$, editors. Antiretroviral Agents and Treatment of HIV Infection. $12^{\text {th }}$ ed. New York: Mc Graw Hill; 2011:1635.

30. Katzung BG, Trevor AJ. Basic and Clinical Pharmacology. In: Safrin S, editors. Antiviral Agents. $13^{\text {th }}$ ed. India: Mc Graw Hill; 2015:848.

31. Prasad A, Datta PP, Bhattacharya J, Pattanayak C, Chauhan AS. Pattern of adverse drug reactions due to cancer chemotherapy in a tertiary care teaching hospital in Eastern India. J Pharmacovigilance. 2013;1:107.

32. Poddar S, Sultana R, Sultana R, Akbor MM, Azad MA, Hasnat A. Pattern of adverse drug reactions due to cancer chemotherapy in tertiary care teaching hospital in Bangladesh. Dhaka Univ J Pharm Sci. 2009;8:11-6.

33. Mallik S, Palaian S, Ojha P, Mishra P. Pattern of adverse drug reactions due to cancer chemotherapy in a tertiary care teaching hospital in Nepal. Pak J Pharm Sci. 2007;20:214-8.

34. Lau PM, Stewart K, Dooley M. The ten most common adverse drug reactions (ADRs) in oncology patients: do they matter to you? Support Care Cancer. 2004;12:626-33.

Cite this article as: Sood A, Sood V, Prajapati H, Sharma A, Bansal R, Mahajan V.

Pharmacovigilance analysis in a rural tertiary care hospital in North India: a retrospective study. Int J Basic Clin Pharmacol 2016;5:1425-31. 